\title{
Responses of the Physiological and Biochemical Characteristics of Alfalfa Roots with Different Root Collar Diameters to Low Temperatures Under Simulated Winter Irrigation
}

\author{
Aimin Zhu \\ Inner Mongolia Agricultural University \\ Qingxin Zhang \\ Agricultural College, Inner Mongolia University for Nationalities \\ Xiaoyan Du \\ Agricultural College, Inner Mongolia University for Nationalities \\ Xianguo Wang \\ China Agricultural University \\ Yuxia Zhang ( $\nabla$ yuxiazhang685@163.com) \\ Agricultural College, Inner Mongolia University for Nationalities \\ Baiming Cong \\ Tongliao Institute of Agriculture and Animal Husbandry \\ Yonglei Tian \\ Academy of Agriculture and Animal Husbandry Sciences, Inner Mongolia
}

\section{Research Article}

Keywords: Alfalfa, Cold resistance, Low-temperature stress, Physiology and biochemistry, Root collar diameter, Winter irrigation

Posted Date: June 16th, 2021

DOl: https://doi.org/10.21203/rs.3.rs-583000/v1

License: (9) (1) This work is licensed under a Creative Commons Attribution 4.0 International License. Read Full License 


\section{Abstract}

Background: Due to the frequent occurrence of extremely low temperatures in northern China, the problem of alfalfa mortality during overwintering requires urgent solutions to support the development of large-scale alfalfa production in the region. Understanding the effects of winter irrigation and the alfalfa root collar diameter on physiological and biochemical cold resistance mechanisms in alfalfa will be of great significance to finding such solutions.

Methods: In this study, alfalfa roots with different root collar diameters $(3.50 \pm 0.10 \mathrm{~mm}, 5.25 \pm 0.10 \mathrm{~mm}, 7.00 \pm 0.10 \mathrm{~mm})$ were subjected to simulated winter irrigation $(0 \mathrm{ml}, 20 \mathrm{ml}, 40 \mathrm{ml})$ and different low-temperature stress treatments $\left(4^{\circ} \mathrm{C},-10^{\circ} \mathrm{C},-15^{\circ} \mathrm{C},-20^{\circ} \mathrm{C}\right)$ in the laboratory. The relationships between alfalfa root collar activity, relative conductivity and the nonstructural carbon and nitrogen contents and antioxidant enzyme activity in the collar were explored.

Results: Low-temperature stress was the most important factor causing significant changes in the physiological and biochemical indexes of the alfalfa root collar, followed by the root collar diameter. Low-temperature stress and the root collar diameter had significant effects on nonstructural carbon and nitrogen levels and enzyme activity (except POD activity) in alfalfa root collars, and winter irrigation had extremely significant effects on the nonstructural nitrogen contents of alfalfa root collars. The larger the diameter of the root collar was, the higher the soluble protein content and the stronger the SOD activity. Simulated winter irrigation increased the C/N ratio in the alfalfa root collars. The increases in nonstructural carbon content, $\mathrm{C} / \mathrm{N}$ ratio and SOD activity in alfalfa root collars helped improve alfalfa cold resistance.

Conclusions: Alfalfa resists low-temperature stress by adjusting the proportions of nonstructural carbon and nitrogen as well as the SOD activity in the root collar. Therefore, fertilization, early sowing and other management measures should be adopted to ensure healthy alfalfa growth and thereby increase the root collar diameter of alfalfa grown in cold regions in northern China. Moreover, timely supplementary irrigation to reach soil saturation in winter can play an important role in improving cold resistance in alfalfa.

\section{Background}

Temperature affects not only the geographical distribution of alfalfa but also the sustainable utilization of artificial alfalfa (Medicago sativa L.) grasslands. In recent years, alfalfa production in northern China has experienced great losses due to freezing damage caused by low temperatures. Although overwintering problems have long plagued alfalfa production, they have not received enough attention ${ }^{[1]}$. Due to the continuous expansion of alfalfa planting areas and the rapid development of the alfalfa industry in recent years, overwintering problems have become critical constraints on the successful establishment and sustainable utilization of artificial alfalfa grasslands in northern China.

Arukerqin Banner, Chifeng city, which is known as the capital of Chinese grass production, has a large-scale alfalfa planting area of more than $70000 \mathrm{hm}^{2}$ in a sandy grassland ${ }^{[2]}$. In recent years, in the water-saving irrigation planting area of the Chifeng sandy land, alfalfa mortality during overwintering has occurred intermittently. For example, in 2014, the mortality rate of overwintering alfalfa under watersaving irrigation reached $50 \%$. In the spring of 2016 , the overwintering survival rate in large-scale alfalfa planting areas was low. In 2018 , the overwintering survival rate of alfalfa was less than $50 \%$, which caused great economic losses to businesses, farmers and herders ${ }^{[3]}$. The low overwintering survival rate of alfalfa in sandy lands has seriously affected the enthusiasm of businesses, cooperatives, farmers and herders for planting alfalfa and has restricted the development of the alfalfa industry in Inner Mongolia. The key to the success of the construction and sustainable utilization of artificial alfalfa grasslands is to adopt reasonable management measures to improve cold resistance in alfalfa ${ }^{[3]}$.

Many studies have been performed on alfalfa cold resistance worldwide ${ }^{[4-7]}$. The results of such studies have shown that cold resistance in alfalfa is related to the activity of root protection enzymes ${ }^{[8-12]}$. Kou et al. ${ }^{[13]}$ and Zhu et al. ${ }^{[14]}$ showed that alfalfa could resist freezing injury by enhancing the activity of antioxidant enzymes in the root collar during a low-temperature stress period. In addition to the close relationship between the activities of antioxidant enzymes and cold resistance in alfalfa, the contents of nonstructural carbon and nitrogen in the alfalfa root collar also exhibit different responses to low temperatures ${ }^{[15-17]}$. Krasnuk et al. ${ }^{[18]}$ showed that low-temperature stress could significantly increase the content of soluble protein in alfalfa roots. Trunova ${ }^{[19]}$ and Wilding et al. ${ }^{[20]}$ considered that an increase in soluble protein content helped to improve cold resistance in plants. Nan et al. ${ }^{[21]}$ showed that the soluble protein, proline and soluble sugar contents in alfalfa root increased with decreasing temperature. In addition, the free proline in plants is an important osmotic regulator that plays an important role in maintaining the osmotic balance between the protoplasm and 
the environment ${ }^{[22]}$. Alfalfa can resist low-temperature stress with its own protective mechanisms within a certain temperature range, but its cold tolerance threshold and its physiological and biochemical processes under different low-temperature stresses need to be further studied.

Whether alfalfa can safely survive the winter depends on the strength of its cold resistance mechanisms but is also influenced by environmental factors and agricultural practices. Winter irrigation and early sowing play important roles in improving cold resistance in alfalfa.

Sun et al. ${ }^{[23]}$ proposed that the key reason for the success or failure of alfalfa regrowth in spring is winter irrigation. Winter irrigation can increase soil moisture levels, improve the heat preservation ability of soils, slow the decline in soil temperatures, help alfalfa resist damage from severe cold, help surface soils freeze, improve the ability of soil to resist wind erosion, and help alfalfa resist severe cold and drought stress in the following spring ${ }^{[24,25]}$. Schwab et al. ${ }^{[5,26]}$ found that the thicker the root collar was, the stronger the cold tolerance of alfalfa. Timely and early sowing is conducive to normal alfalfa growth and development. It allows alfalfa plants to have a long enough growth period to synthesize and transport sufficient nutrients for storage in the roots; having more nutrients stored in roots in the winter is conducive to safe overwintering for alfalfa. However, the contributions of winter irrigation and the root collar diameter to alfalfa cold resistance and the mechanisms of the physiological and biochemical changes in alfalfa during this process are still unclear. This study aimed to explore the physiological and biochemical mechanisms of cold resistance adaptation in alfalfa plants with different root diameters after simulated winter irrigation. Because of the complex environment and the many uncontrollable factors in the field, in this study, alfalfa roots with different root collar diameters were treated with low-temperature stress after simulated winter irrigation in the laboratory. The effects of low temperature, water application and root collar diameter on various physiological and biochemical indexes of the alfalfa root collars were analyzed. Exploring the factors affecting alfalfa overwintering in a sandy land and the physiological and biochemical mechanisms of root collar cold resistance will be of great significance for guiding efficient alfalfa production in the cold areas of northern China.

\section{Results}

As shown in Table 1, the alfalfa root collar diameter and low-temperature stress had significant effects on all physiological and biochemical indexes of the root collar except for POD activity. The simulated winter irrigation treatment had significant effects on the relative conductivity, activity, free amino acid content, soluble protein content and nonstructural $\mathrm{C} / \mathrm{N}$ ratio of the alfalfa root collar but had no significant effects on the soluble sugar and starch contents or antioxidant enzyme activity of the root collar. The interaction of the root collar diameter and low-temperature stress had significant effects on all physiological and biochemical indexes except the soluble sugar content. The interaction of the root collar diameter and winter irrigation had significant effects on alfalfa root collar activity and the $\mathrm{C} / \mathrm{N}$ ratio. The interaction of low-temperature stress and winter irrigation had significant effects on alfalfa root collar activity and soluble protein content. The interaction of the root collar diameter, low-temperature stress and winter irrigation had significant effects on the relative conductivity; activity; soluble sugar, starch, malondialdehyde contents; and $\mathrm{C} / \mathrm{N}$ ratio of the root collar but had no significant effect on the other physiological and biochemical indexes. 
Table 1

Effects of treatment and interaction on physiological and biochemical indexes of alfalfa

\begin{tabular}{|c|c|c|c|c|c|c|c|c|c|c|c|c|c|c|}
\hline \multirow{2}{*}{$\begin{array}{l}\text { Treatment } \\
\text { Index }\end{array}$} & \multicolumn{2}{|c|}{ RCD } & \multicolumn{2}{|c|}{ LTS } & \multicolumn{2}{|c|}{ swW } & \multicolumn{2}{|c|}{ RCD $\times$ LTS } & \multicolumn{2}{|c|}{ RCD×SWW } & \multicolumn{2}{|c|}{ LTS×SWW } & \multicolumn{2}{|c|}{ RCD $\times L T S \times S W W$} \\
\hline & df & F-value & df & F-value & df & F-value & df & F-value & df & F-value & df & F-value & df & F-value \\
\hline $\mathrm{RC}$ & 2 & $18.199 * \star$ & 3 & $329.989 * \star$ & 2 & $3.706^{*}$ & 6 & $8.764^{\star \star}$ & 4 & 1.022 & 6 & 2.134 & 12 & $2.623^{\star *}$ \\
\hline RCA & 2 & $4.542^{\star}$ & 3 & $329.441^{\star \star}$ & 2 & $3.622^{\star}$ & 6 & $11.79 \star \star$ & 4 & $7.731^{\star \star}$ & 6 & $3.784^{\star \star}$ & 12 & $2.791^{\star \star}$ \\
\hline SS & 2 & $24.662^{\star \star}$ & 3 & $36.148^{\star *}$ & 2 & 1.321 & 6 & 2.104 & 4 & 1.801 & 6 & 0.715 & 12 & $1.999 *$ \\
\hline$S$ & 2 & $21.602^{\star \star}$ & 3 & $68.135^{\star \star}$ & 2 & 2.374 & 6 & $7.465^{\star \star}$ & 4 & 1.809 & 6 & 1.241 & 12 & $2.044^{\star}$ \\
\hline FAA & 2 & $9.204^{\star \star}$ & 3 & $37.678^{\star \star}$ & 2 & $6.137^{\star \star}$ & 6 & $3.978^{\star \star}$ & 4 & 0.836 & 6 & 1.712 & 12 & 1.785 \\
\hline SP & 2 & $24.001 \star \star$ & 3 & $81.683^{\star \star}$ & 2 & 8.936 ** & 6 & $8.243^{\star \star}$ & 4 & 2.118 & 6 & $2.606^{*}$ & 12 & 1.681 \\
\hline SOD & 2 & $5.902^{* *}$ & 3 & $6.329 * *$ & 2 & 0.047 & 6 & $6.323^{\star \star}$ & 4 & 2.241 & 6 & 0.130 & 12 & 1.052 \\
\hline POD & 2 & 0.626 & 3 & 2.603 & 2 & 1.021 & 6 & $3.158^{\star \star}$ & 4 & 1.740 & 6 & 0.295 & 12 & 1.076 \\
\hline CAT & 2 & $3.476^{*}$ & 3 & $15.002^{\star \star}$ & 2 & 0.472 & 6 & $2.418^{\star}$ & 4 & 1.812 & 6 & 1.209 & 12 & 1.004 \\
\hline MDA & 2 & $7.335^{\star \star}$ & 3 & $4.661^{\star \star}$ & 2 & 0.737 & 6 & $3.039 *$ & 4 & 1.259 & 6 & 1.448 & 12 & $4.436^{\star \star}$ \\
\hline $\mathrm{C} / \mathrm{N}$ & 2 & $35.204^{\star \star}$ & 3 & $85.712^{\star \star}$ & 2 & $4.465^{\star}$ & 6 & $5.821^{\star \star}$ & 4 & $3.334^{*}$ & 6 & 1.523 & 12 & $4.044^{\star \star}$ \\
\hline \multicolumn{15}{|c|}{$\begin{array}{l}\text { RCD, LTS and SWW represent the alfalfa root collar diameter, low-temperature stress and simulated winter irrigation treatment, } \\
\text { respectively. RCD } \times \text { LTS, RCD } \times \text { SWW, LTS } \times \text { SWW and RCD } \times \text { LTS } \times \text { SWW represent the interactions among the RCD and the } \\
\text { treatments. RC, RCA, SS, S, FAA, SP, SOD, POD, CAT, MDA And C/N refer to the relative conductivity activity; soluble sugar, starch, free } \\
\text { amino acid, and soluble protein contents; superoxide dismutase, peroxidase, and catalase activity; malondialdehyde content and } \\
\text { nonstructural carbon to nitrogen ratio of the root collars, respectively. df and F-value refer to the degrees of freedom and the F value, } \\
\text { respectively. *: The treatment had a significant effect on the index at the } 0.05 \text { significance level; **: the treatment had a significant } \\
\text { effect on the index at the } 0.01 \text { significance level. }\end{array}$} \\
\hline
\end{tabular}

In this experiment, the RI was used to characterize the effects of the root collar diameter, the treatments (temperature and winter irrigation) and their interactions on the physiological and biochemical indexes of the alfalfa root collars. Figure 1 shows that the lowtemperature stress treatment had the greatest impact on the physiological and biochemical indexes of the alfalfa root collars, followed by the root collar diameter and the interaction between the root collar diameter and low-temperature stress; the winter irrigation treatment and the interactions related to the winter irrigation treatment had little impact on the physiological and biochemical indexes of the alfalfa root collars.

With decreasing stress temperature, the alfalfa root collar activity decreased gradually (Fig. 2 ). The activity of the root collar at $4^{\circ} \mathrm{C}$ was significantly higher than that at $-10^{\circ} \mathrm{C},-15^{\circ} \mathrm{C}$, and $-20^{\circ} \mathrm{C}$. The activity of the root collar at $-20^{\circ} \mathrm{C}$ was the lowest, at $0.1076 \mu \mathrm{g} \cdot \mathrm{g}^{-1} \cdot \mathrm{h}^{-1}$. When the temperature reached $-15^{\circ} \mathrm{C}$, the relative conductivity of the alfalfa root collar did not increase with decreasing temperature. The relative conductivity at $4^{\circ} \mathrm{C}$ was the lowest and was significantly lower than that in the other low-temperature treatments. There was no significant difference in relative conductivity between $-15^{\circ} \mathrm{C}$ and $-20^{\circ} \mathrm{C}$.

As shown in Fig. 3, with decreasing temperature, the contents of soluble sugars and free amino acids and the POD activity in the alfalfa root collar increased, decreased, and increased again. These indexes reached peak values at - $10^{\circ} \mathrm{C}$; they decreased significantly from $10^{\circ} \mathrm{C}$ to $-15^{\circ} \mathrm{C}$ and increased significantly from $-15^{\circ} \mathrm{C}$ to $20^{\circ} \mathrm{C}$. The soluble sugar content and POD activity reached a maximum at $-20^{\circ} \mathrm{C}$, and the free amino acid content reached a maximum at $-10^{\circ} \mathrm{C}$. The starch content, $\mathrm{C} / \mathrm{N}$ ratio, SOD activity, CAT activity and MDA content of the alfalfa roots decreased with increasing temperature. The starch content, CAT activity and MDA content were the highest at - $10^{\circ} \mathrm{C}$; these values were significantly higher than those at $4^{\circ} \mathrm{C}$ and $-20^{\circ} \mathrm{C}$. The $\mathrm{C} / \mathrm{N}$ ratio and SOD activity were the highest at $-15^{\circ} \mathrm{C}$; these values were significantly higher than those at other temperatures. Among the various indexes, the soluble protein content was the only index to decrease first and then increase with increasing temperature; it reached a minimum at $-15^{\circ} \mathrm{C}$ and was significantly lower than at other temperatures, then increased nonsignificantly at $4^{\circ} \mathrm{C}$ and $-20^{\circ} \mathrm{C}$.

As shown in Fig. 4, the treatments with no and $20 \mathrm{ml}$ of winter irrigation had no significant effect on the relative electrical conductivity or root collar activity of alfalfa. However, when $40 \mathrm{ml}$ of winter irrigation was added, the relative electrical conductivity of the alfalfa root collar increased significantly, while the root collar activity decreased significantly. The temperature changes in the temperature control boxes are different from those that occur in field soil. The temperature change in a temperature control box affects the whole box, and 
the whole root system of alfalfa experiences the external low-temperature stress at the same time. In the field, soil temperature change is a slow, gradual process that begins with a change in the air temperature and progresses downward from the soil surface.

As shown in Fig. 5, With the increase in the amount of simulated winter irrigation applied, the contents of starch, soluble protein and free amino acids in the alfalfa roots decreased gradually, and they decreased significantly compared with those in the control when $40 \mathrm{ml}$ of simulated winter irrigation was applied. The $\mathrm{C} / \mathrm{N}$ ratio increased with the increase in applied simulated winter irrigation, and the $\mathrm{C} / \mathrm{N}$ ratio under $40 \mathrm{ml}$ of winter irrigation was significantly higher than that under no irrigation. The soluble sugar content; SOD, POD, and CAT activities, and MDA content were not significantly affected by the simulated irrigation.

The root collar diameter had certain effects on the relative conductivity and activity of the root collars (Fig. 6). With the increase in root collar diameter, the relative conductivity decreased significantly. The activity of the root collar was not significantly different between 3.5 $\mathrm{cm}$ and $5.25 \mathrm{~cm}$ but increased significantly compared with that at $5.25 \mathrm{~cm}$ when the diameter of the root collar reached $7 \mathrm{~cm}$. This result indicated that the larger the diameter of an alfalfa rhizome is, the weaker the effect of low-temperature stress.

As shown in Fig. 7, The soluble sugar, starch and free amino acid contents and the $\mathrm{C} / \mathrm{N}$ ratio were the highest and were significantly greater than those at $5.25 \mathrm{~cm}$ when the diameter of the root collar was $3.5 \mathrm{~cm}$. The starch content, free amino acid content and C/N ratio were not significantly different between $5.25 \mathrm{~cm}$ and $7 \mathrm{~cm}$ in collar diameter. The contents of soluble protein and MDA increased with increasing root collar diameter, but the activity of SOD decreased significantly. The CAT activity at $5.25 \mathrm{~cm}$ was significantly higher than that at $3.5 \mathrm{~cm}$ and $7 \mathrm{~cm}$. In addition, the diameter of the root collar had no significant effect on POD activity in the root collar.

The correlation analysis between the diameter class and treatments and the indexes showed that there was a significant negative correlation between the root collar diameter and the starch content, soluble protein content and $\mathrm{C} / \mathrm{N}$ ratio in the root collar. There was a significant negative correlation between the treatment temperature and the relative conductance, soluble sugar and $\mathrm{C} / \mathrm{N}$ ratio of the alfalfa root collar and a significant positive correlation between the treatment temperature and the root collar activity (Table 2). There was a significant negative correlation between the winter irrigation level and the contents of free amino acids and soluble protein.

Table 2

Correlation analysis between treatment and physiological and biochemical indexes of alfalfa root collar

\begin{tabular}{|c|c|c|c|c|c|c|c|c|c|c|c|}
\hline $\begin{array}{l}\text { Index } \\
\text { Treatm }\end{array}$ & $\mathrm{RC}$ & RCA & SS & $s$ & FAA & SP & SOD & POD & CAT & MDA & $\mathrm{C} / \mathrm{N}$ \\
\hline RCD & -0.174 & 0.082 & 0.035 & $-0.252^{\star \star}$ & -0.169 & $0.317^{\star \star}$ & $-0.269 \star \star$ & -0.070 & 0.036 & $0.266^{\star \star}$ & $-0.284^{\star \star}$ \\
\hline LTS & $-0.861^{\star \star}$ & $0.888^{\star \star}$ & $-0.441 * \star$ & -0.006 & 0.031 & $0.341^{\star \star}$ & -0.107 & -0.072 & 0.184 & 0.089 & $-0.464^{\star \star}$ \\
\hline swW & 0.059 & -0.073 & -0.057 & -0.106 & $-0.206^{*}$ & $-0.190 \star$ & -0.020 & -0.097 & 0.059 & -0.087 & 0.130 \\
\hline
\end{tabular}

The relative conductivity and activity of the root collar are important criteria for characterizing cold resistance in alfalfa. The results showed that the relative conductivity of the alfalfa root collar had a very significant positive correlation with the soluble sugar content and $\mathrm{C} / \mathrm{N}$ ratio, a significant positive correlation with the starch content and SOD activity, a very significant negative correlation with the soluble protein content, and a significant negative correlation with the free amino acid content (Table 3 ). The root collar activity was negatively correlated with the soluble sugar content and $\mathrm{C} / \mathrm{N}$ ratio and positively correlated with the soluble protein content and CAT activity.

Table 3 Correlation analysis of relative electrical conductivity, root collar activity and physiological and biochemical indexes of alfalfa

\begin{tabular}{|llllllllll|}
\hline Index & SS & S & FAA & SP & SOD & POD & CAT & MDA & C/N \\
\hline RC & $0.301 * *$ & $0.227 *$ & $-0.191^{*}$ & $-0.469 * *$ & $0.190 *$ & 0.060 & -0.130 & -0.174 & $0.619 * *$ \\
\hline RCA & $-0.387 * *$ & -0.040 & -0.047 & $0.351 * *$ & -0.112 & -0.043 & $0.275^{\star *}$ & 0.118 & $-0.474 * *$ \\
\hline
\end{tabular}

**: Represents a significant correlation at the 0.01 level $(P<0.01)$, *: Represents a significant correlation at the 0.05 level $(P<0.05)$. 


\section{Discussion}

Understanding the physiological and biochemical mechanisms of cold resistance in alfalfa under different winter irrigation levels and different diameters of alfalfa root collars is very important for improving cold resistance in alfalfa. Alfalfa overwintering is a complex process that can be considered to include biological (fungi, bacteria, etc.) and abiotic (frost, frost heaving, drought, etc.) stress factors [4] When plants are damaged by low temperatures, the permeability of the cell plasma membranes changes greatly, and electrolytes are exosmosed to varying degrees. Cells with strong cold resistance or little damage not only have low permeability but can also reverse their permeability, which allows them to easily return to normal conditions; in contrast, cells with weak cold resistance or severe damage cannot return to normal, which leads to injury or cell death ${ }^{[27]}$. Zhu et al. ${ }^{[28]}$ showed that the root collar activity in alfalfa plants decreased significantly after low-temperature stress, while the relative electrical conductivity of root collars increased significantly; cold resistance in the plants could be determined by measuring the relative electrical conductivity and root collar activity of alfalfa. The same conclusion was reached in this study. The results showed that the root collar activity and relative conductivity of alfalfa were extremely sensitive to low temperatures. Therefore, the root collar activity and relative conductivity of alfalfa were used as important indexes for analyzing cold resistance in alfalfa.

Previous studies have shown that increases in the soluble sugar, soluble protein and free amino acid contents in alfalfa root collars can have a positive effect on improving cold resistance ${ }^{[19,20]}$. However, the conclusion of this study is that the $\mathrm{C} / \mathrm{N}$ ratio of the alfalfa root collar increases due to an increase in the content of soluble sugar and a reduction in the contents of soluble protein and free amino acids; both of these changes increase cold resistance in alfalfa. The content of nonstructural nitrogen in the root collar of alfalfa increases after the overwintering period begins, but the increase range of the soluble sugar content in the root collar is greater than that of nonstructural proteins, so the $\mathrm{C} / \mathrm{N}$ ratio is also higher. This self-regulation mechanism for coping with low-temperature environments is undoubtedly the most effective manifestation of alfalfa improving its cold resistance. Why did the contents of soluble protein and free amino acids decrease during the early stage of the low-temperature treatment? They may have decreased because this experiment is an indoor, controlled experiment. The temperature in the temperature-controlled boxes was lowered to the target temperature at $4^{\circ} \mathrm{C}$ per hour. This temperature change is rapid compared with those in the field environment, and the self-regulation mechanisms in alfalfa roots may have struggled to become activated within this short time period. Alfalfa improves its cold resistance by increasing the soluble sugar content in its root collar and reducing the soluble protein and free amino acid contents to regulate the nonstructural $\mathrm{C} / \mathrm{N}$ ratio. The $\mathrm{C} / \mathrm{N}$ ratio indirectly reflects the contents of nonstructural carbon and nitrogen in plant tissues and is one of the indicators used to measure plant stress resistance. Studies have shown that the higher the $\mathrm{C} / \mathrm{N}$ ratio is, the more favorable it is for plant overwintering success ${ }^{[29]}$. The correlation analysis in this study also showed that the $\mathrm{C} / \mathrm{N}$ ratio had a very significant positive correlation with plant cold resistance. Therefore, the value of the nonstructural $\mathrm{C} / \mathrm{N}$ ratio in the alfalfa root collar can be used as the criterion for assessing cold resistance.

The increase in the activities of protective enzymes (SOD, POD and CAT) in the root collar of alfalfa plays an important role in improving cold resistance in alfalfa. Wang et al. ${ }^{[30]}$ summarized the research progress on cold resistance in alfalfa in Australia and showed that the antioxidant enzyme activity of alfalfa roots was higher in cold, high-altitude areas than in other areas. Qi ${ }^{[31]}$ showed that the activity of POD in alfalfa leaves first increased and then decreased with decreasing temperature, indicating that alfalfa could resist low-temperature stress by enhancing the activity of POD in leaves under short-term low-temperature treatments. In this study, as the temperature continued to decrease, the activity of POD decreased, while the activity of SOD increased significantly. Yang's study showed that the activities of SOD, POD and CAT in the alfalfa root collar first increased and then decreased with decreasing temperature and reached a maximum in early winter. In midwinter, the activities of the three enzymes fluctuated to varying degrees but decreased significantly overall. In this study, low-temperature stress had no significant effect on POD activity in the root collar of alfalfa but had a significant effect on SOD and CAT activity, both of which first increased and then decreased with decreasing treatment temperature. However, the difference between SOD and CAT was that SOD activity was the strongest at $-15^{\circ} \mathrm{C}$, while CAT activity was the strongest at $-10^{\circ} \mathrm{C}$. Therefore, we suggest that the increase in SOD and CAT activities in the alfalfa root collar is conducive to cold stress resistance and that when alfalfa reaches its stress tolerance limit, the enzyme activity will cease to increase.

Winter irrigation is considered to be an important management technique for reducing frost damage in alfalfa ${ }^{[32,33]}$. To some extent, the simulated winter irrigation in this study slowed the drastic change in soil temperature and thereby reduced freezing damage in the alfalfa plants. The results showed that the $\mathrm{C} / \mathrm{N}$ ratio of the alfalfa root collar increased with the increase in simulated winter irrigation, and the $\mathrm{C} / \mathrm{N}$ ratio was the highest when sufficient water was provided to saturate the soil. Therefore, the mechanism by which winter irrigation increases cold resistance in alfalfa may be related to the metabolism of carbon and nitrogen in the root collar. Alfalfa root collars that are larger in diameter will exhibit stronger activity in the root collar and lower relative conductivity; therefore, they will experience less damage under low-temperature conditions. Moreover, there is a very significant positive correlation between the root collar diameter and the 
soluble protein content, which indicates that the accumulation of soluble protein in the root collar helps to alleviate freezing damage in alfalfa; this finding is consistent with previous research results $[14,19,20]$.

\section{Conclusions}

Low-temperature stress is the most important factor causing significant changes in the physiological and biochemical indexes of alfalfa root collars. Increases in the nonstructural carbon content and $\mathrm{C} / \mathrm{N}$ ratio and the SOD activity in the alfalfa root collar help to improve cold resistance in alfalfa. Alfalfa root collars had higher $\mathrm{C} / \mathrm{N}$ ratios at the highest level of simulated winter irrigation. Alfalfa with larger root collars had higher collar activity and soluble protein contents under low-temperature stress than alfalfa with smaller root collars; these factors helped the alfalfa with larger root collars better resist low-temperature stress. Therefore, fertilization, early sowing and other management measures should be adopted to ensure healthy alfalfa growth in the cold northern regions of China and to increase the root collar diameters of alfalfa plants. In addition, timely supplementary irrigation to reach soil saturation in winter can play an important role in improving cold resistance in alfalfa.

\section{Methods}

\section{Field experiments}

The experimental material was Gongnong No. 1 alfalfa (Medicago sativa L. Gongnong No. 1) provided by the Grassland Research Institute of the Jilin Academy of Agricultural Sciences. The experimental site was located in the grass production base of Ar Horqin Banner near the Nei Mongol Autonomous Region, China (coordinates 42 $30^{\prime} 50.4^{\prime \prime} \mathrm{N} ; 115^{\circ} 27^{\prime} 34.2^{\prime \prime} \mathrm{E}$ ). The nutrient composition of the soil is shown in Table 4. On July 1st, 2017, sowing was carried out by mechanical seeding at a rate of $22.5 \mathrm{~kg} \cdot \mathrm{hm}^{-2}$.

Table 4

Soil nutrient contents at the test site

\begin{tabular}{llllll} 
Index & $\begin{array}{l}\text { Alkaline nitrogen } \\
\left(\mathrm{mg} \cdot \mathrm{kg}^{-1}\right)\end{array}$ & $\begin{array}{l}\text { Available phosphorus } \\
\left(\mathrm{mg} \cdot \mathrm{kg}^{-1}\right)\end{array}$ & $\begin{array}{l}\text { Available potassium } \\
\left(\mathrm{mg} \cdot \mathrm{kg}^{-1}\right)\end{array}$ & $\begin{array}{l}\text { Organic matter } \\
\left(\mathrm{mg} \cdot \mathrm{kg}^{-1}\right)\end{array}$ & $\begin{array}{l}\mathrm{pH} \\
\text { value }\end{array}$ \\
\hline Content & 38.80 & 2.10 & 103.00 & 7.28 & 7.26
\end{tabular}

\section{Sampling and measurements}

Alfalfa roots were sampled during the soil freezing and thawing period on November 10, 2017, and the excavation depth was approximately $20 \mathrm{~cm}$. A Vernier caliper was used to measure root collar of alfalfa in the laboratory. The alfalfa roots were divided into three categories by root collar diameter $(3.50 \pm 0.10 \mathrm{~mm}, 5.25 \pm 0.10 \mathrm{~mm}$ and $7.00 \pm 0.10 \mathrm{~mm})$ and stored at $4{ }^{\circ} \mathrm{C}$ in a refrigerator.

\section{Experimental design of the low-temperature treatment}

The sampled overwintering organs (roots) of alfalfa in the three diameter classes $(3.50 \pm 0.10 \mathrm{~mm}, 5.25 \pm 0.10 \mathrm{~mm}$, and $7.00 \pm 0.10$ $\mathrm{mm}$ ) were washed with distilled water. We grouped the treatments as shown in Table 5. Each treatment was repeated 3 times, and each replicate included 10 alfalfa roots. The length of the roots in all treatments was standardized to $15 \mathrm{~cm}$. The roots were placed side by side on $30 \mathrm{~cm} \times 20 \mathrm{~cm}$ pieces of absorbent cotton with a thickness of $3 \mathrm{~mm}$. After wrapping the roots in the absorbent cotton, 0 (control), $20 \mathrm{ml}$ ( $50 \%$ of the soil water-holding capacity) or $40 \mathrm{ml}$ ( $80 \%$ of the soil water-holding capacity) of distilled water was sprayed onto the wrapped roots. Finally, the cotton-wrapped roots were enclosed in $30 \mathrm{~cm} \times 30 \mathrm{~cm}$ pieces of tin foil. Alfalfa root materials kept in a refrigerator at a constant temperature of $4{ }^{\circ} \mathrm{C}$ were used as controls. The roots in the other treatments were placed into programmable, temperature-controlled boxes for the low-temperature treatments. The target temperatures of the treatments were $-10{ }^{\circ} \mathrm{C},-15^{\circ} \mathrm{C}$ and -20 ${ }^{\circ} \mathrm{C}$. Each temperature control box was set as follows: the starting temperature was $4{ }^{\circ} \mathrm{C}$; the temperature was reduced to the target temperature at a rate of $4{ }^{\circ} \mathrm{C} \cdot \mathrm{h}^{-1}$ and then maintained for $6 \mathrm{~h}$; then, the temperature was raised at a rate of $4{ }^{\circ} \mathrm{C} \cdot \mathrm{h}^{-1}$ to reach room temperature. The roots were then removed from the boxes and kept at $4{ }^{\circ} \mathrm{C}$ for $12 \mathrm{~h}$, at which point the relevant indexes were measured ${ }^{[3}$, 28]. 
Table 5

Experimental design

\begin{tabular}{|llllllllllll}
\hline Treatment temperature & \multicolumn{3}{l}{$-10^{\circ} \mathrm{C}$} & & & & & & & 4 \\
\hline
\end{tabular}

\section{Measurement indexes and methods ${ }^{\text {[34-36] }}$}

After the low-temperature treatments, the alfalfa root collars $(0-0.5 \mathrm{~cm})$ were sampled with a blade and sliced for the determinations of root collar activity, relative conductivity, nonstructural carbon and nitrogen contents and antioxidant enzyme activity. The root activity was determined by TTC staining. The soluble protein content was determined by the Coomassie brilliant blue method. The soluble sugar and the starch content were determined by anthrone colorimetry. The free amino acid content was determined by ninhydrin staining. The malondialdehyde content was determined by the thiobarbituric acid method. Superoxide dismutase (SOD) activity was determined by the nitro-blue tetrazolium method. Catalase (CAT) activity was determined by the UV absorption method. Peroxidase (POD) activity was determined by the guaiacol method. The relative conductivity was measured by the electrolyte permeation method. The nonstructural $\mathrm{C} / \mathrm{N}$ ratio was calculated as $\mathrm{C} / \mathrm{N}=$ (soluble sugar content + starch content) / (free amino acid content + soluble protein content) ${ }^{\text {[37] }}$.

\section{Statistical analyses}

Microsoft Excel software was used for data calculation and tabulation, and SigmaPlot software was used to generate the figures. SPSS 17.0 software was used to analyze the significance of the variance of three factors (root collar diameter, irrigation level and temperature) with regard to the relative electrical conductivity, activity, antioxidant enzyme activity and nonstructural carbon and nitrogen in the root collars. The correlations between the physiological and biochemical indexes of the alfalfa root collar and the activity and relative electrical conductivity of the root collar at low temperatures were analyzed. The response index $(\mathrm{RI})$ was calculated as $\mathrm{RI}=(0.5 \mathrm{x}+$ $1.0 \mathrm{y}) / \mathrm{N}$, where $\mathrm{x}$ is the number of indicators that had a significant impact, $\mathrm{y}$ is the number of indicators that had an extremely significant impact, and $\mathrm{N}$ is the total number of indicators. A treatment that had a significant effect on the RI at $P<0.05$ was recorded as a value of 0.5; a treatment that had an extremely significant effect on the RI at $P<0.01$ was recorded as 1.0 ; and a treatment that had no significant effect on the index $(P>0.05)$ was recorded as 0 .

\section{Abbreviations}

RCD: root collar diameter; LTS: low-temperature stress; SWW: simulated winter irrigation; RC囚relative conductivity; RCA囚root collar activity; SS: soluble sugar; S: starch; FAA: free amino acid; SP: soluble protein; SOD: superoxide dismutase; POD: peroxidase; CAT: catalase; MDA: malondialdehyde; $\mathrm{C} / \mathrm{N}$ : ratio of unstructured carbon to nitrogen.

\section{Declarations}

\section{Ethics approval and consent to participate}

The experimental material was Gongnong No. 1 alfalfa (Medicago sativa L. Gongnong No. 1) provided by the Grassland Research Institute of the Jilin Academy of Agricultural Sciences. All field experiments were conducted in accordance with Environmental Protection 


\section{Consent for publication}

Not applicable

\section{Availability of data and materials}

The datasets used and/or analysed during the current study are available from the corresponding author on reasonable request.

\section{Competing interests}

All authors declare that they have no competing interests.

\section{Funding}

This work was supported by The Inner Mongolia Natural Science Fund Project (Grant No. 2020MS03081), Inner Mongolia Science and Technology Reserve Project (Grant No. 2018MDCB032), and National Public Welfare Industry (Agriculture) Public Welfare Projects (Grant No. 201403048-2). The funding body had no role in the design of the study and collection, analysis, and interpretation of data and in writing the manuscript.

\section{Authors' contributions}

AMZ was responsible for writing the paper; QXZ and XYD were responsible for managing the experiment; BMC and YLT assisted AMZ in the experiment; and $Y X Z$ and $X G W$ were responsible for the design and management of the experiment. All authors have read and approved the manuscript.

\section{Acknowledgements}

We are very grateful to $Y Z$, the president of Huinong Prataculture company, and his staff for their help in planting alfalfa. Thanks to XW and $\mathrm{WHH}$ for their help in the experiment.

\section{Ethics approval and consent to participate}

The seeds were kindly provided by the Grassland Research Institute of the Jilin Academy of Agricultural Sciences, Jilin, China. The experimental research on plants, including collection of plant material, complied with institutional, national, or international guidelines and complied with the Convention on the Trade in Endangered Species of Wild Fauna and Flora. These materials have been deposited in a publicly available herbarium. All field experiments were conducted in accordance with Environmental Protection law of the People's Republic of China and did not involve endangered or protected species.

\section{Authors' information}

${ }^{1}$ Agricultural College, Inner Mongolia University for Nationalities, Tongliao, 02804, China. ${ }^{2}$ College of Grassland, Resources and Environment, Inner Mongolia Agricultural University, Hohhot, 010019, China. ${ }^{3}$ College of Grassland Science and Technology, China Agricultural University, Beijing, 100083, China. ${ }^{4}$ Laboratory of Animal Nutrition and Feed, Tongliao Institute of Agriculture and Animal Husbandry, Inner Mongolia, Tongliao, 028000, China. ${ }^{5}$ Grassland Research Institute, Academy of Agriculture and Animal Husbandry Sciences, Inner Mongolia, Hohhot, 010031, China.

\section{References}


1. Pu XC. King of forage: alfalfa. Beijing: Taihai Publishing House; 2001.

2. L N. The advantages, problems and countermeasures of the development of forage industry in Alukeerqin Banner. In: Papers of the Sixth China Alfalfa Development Conference and International Alfalfa Conference: China Animal Husbandry Association; 2015. p. 5.

3. Zhu AM, Han GD, Zhang YX, Wang XG, Tian YL, Cong BM. Influence and analysis of different sowing time on overwintering rate of alfalfa. Acta Agrcstia Sin. 2020;28:446-53.

4. Annick B, Yves C. Plant adaptations to overwintering stresses and implications of climate change. Can J Bot. 2003;81:1145-52.

5. Schwab PM, Barnes DK, Sheaffer CC. The relationship between field winter injury and fall growth score for 251 alfalfa cultivars. Crop Sci. 1996;36:418-26.

6. Zhang CZ, Gao MW. A survey on overwinter rate of alfalfa crop in Aluhorqin Banner. Grassl Prataculture. 2014;26:28-9.

7. Zhu AM, Zhang YX, Wang XG, Tian YL, Cong BM, Wang X, Hou WH. Responses of morphological characteristics of different alfalfa varieties to low temperature and their relationship with cold resistance in sandy habitats. Acta Agrcstia Sin. 2018;26:1400-8.

8. Sun QZ, Gui R, Han JG. Research on winter injury and prevent technique of alfalfa (Medicago sativa L. cv. 'Aohan') in Chifeng region. Acta Agrcstia Sin. 2001:50-7.

9. McKersie BD, Chen, Y, Beus M, Bowley SR, Bowler C, Inzé DD', Halluin K, Botterman J. Superoxide dismutase enhances tolerance of freezing stress in transgenic alfalfa (Medicago sativa L.). Plant Physiol. 1993;103:1155-63.

10. Duke SH, Doehlert DC. Root respiration, nodulation, and enzyme activities in alfalfa during cold acclimation. Crop Sci. 1981;21:48995.

11. Liu HX, Zeng SX, Ling P. The relationship between plant cold resistance and enzyme system polymorphism. Plant Physiol Commun. 1981:6-11.

12. Cui GW. The physiological responses of cold resistance in alfalfa during overwintering period in the field. Acta Agrcstia Sin. 2009;17:145-50.

13. Kou JC, Yang WQ, Jia ZK, Han QF, Zhao D. Cold tolerance of different alfalfa varieties. Acta Prataculturae Sin. 2008;30:11-5, 20.

14. Zhu AM, Zhang YX, Wang XG, Tian YL. Effects of cutting treatments in late autumn on antioxidant enzyme activity and proline content in crown of sandy land alfalfa in winter. Acta AQrestia Sin. 2018;26:222-30.

15. Smith D. Winter injury and the survival of forage plants. Herb Abstr. 1964:203-9.

16. Jian LC. The relationship between biofilms and plant cold damage and cold resistance. Chin Bull Bot. 1983:217-20.

17. Du YJ, Yu L, Sun JX, Lu WH. Comprehensive assessment of cold resistance of three Zoysia japonica varieties. Acta Prataculturae Sin. 2008;17:6-16.

18. Krasnuk M, Jung GA, Witham FH. Electrophoretic studies of the relationship of peroxidases, polyphenol oxidase, and indoleacetic acid oxidase to cold tolerance of alfalfa. Cryobiology. 1975;12:62-80.

19. Trunova T. Plant cold hardiness and freezing stress. New York: Academic Press; 1982.

20. Wilding MD, Stahmann MA, Smith D. Free amino acids in alfalfa as related to cold hardiness. Plant Physiol. 1960;35:726-32.

21. Nan LL, Shi SL, Chen JG, Zhu XQ, Guo QE, Zhao WH. Field evaluation of the reponse and resistance to low temperature of alfalfa root with different root types during over-wintering. Chin J Eco Agric. 2011;25:369-74.

22. Delauney AJ, Verma DPS. Proline biosynthesis and osmoregulation in plants. Plant J. 1993;4:215-23.

23. Sun HR, Wu RX, Li PH, Zeng H, Liu JY. The key reason of success or failure of overwintering and reviving of alfalfa in China forage capital. Chin Dairy Cattle. 2015:15-8.

24. Wu RX, Sun HR, Sun YY, Li PH, Xie Y, Liu AH. Research on the optimum time of fall cutting of alfalfa in Beijing plain. Pratacultural Sci. 2009;26:113-8.

25. Sun HR, Liu GR, Zhang YJ, Gao F, Lu TL, Han JG. Water requirement, water consumption, water requirement rate, water consumption rate and water use efficiency of alfalfa. Pratacultural Sci. 2005;22:24-30.

26. Schwab PM, Barnes DK, Sheaffer CC, Li PH. Factors affecting a laboratory evaluation of alfalfa cold tolerance. Crop Sci. 1996;36:318-24.

27. Lyons JM. Chilling injury in plants. Annu Rev Plant Physiol. 1973;24:445-66.

28. Zhu AM, Zhang YX, Wang XG, Tian YL, Cong BM, Zhang QX. Comparison of cold resistance of 8 alfalfa varieties. Journal of Northwest A \& F University (Nat. Sci. Ed.) 2019,47(01):45-52. 
29. Yu H, Liu HQ, Cui GW. Changes in overwintering rate and main-root $\mathrm{C} / \mathrm{N}$ ratio in alfalfa cultivars at different cutting frequency. Chinese Journal of Grassland. 2008;30:21-4.

30. Wang J, Lu X, Yan X, Zhang M. The research progress on cold-resistance characteristics from Australia alfalfa resources. Chinese Agricultural Science Bulletin. 2007:44-7.

31. Qi CY, Liu FQ, Liu JL, Zhu RF, Tang FL. Cluster analysis of antioxidant enzymes and soluble protein of alfalfa hybrid under low temperature stress. Chinese Journal of Grassland. 2017;39:53 - $8+70$.

32. Yang XF, Liang QW, Na RS, Zhang QQ, Pan XL. Technical regulation of alfalfa overwintering management under water saving irrigation in sandy land of central and Eastern Inner Mongolia. Contemp Livest Poult Breed Ind. 2019:37-8.

33. Xu HY, Gao Q, Li ZS, Hang ZY, He F, Li XL. The influence of prior water deficit on alfalfa (Medicago sativa L.) freezing tolerance under two different temperature rhythm. Acta Agrcstia Sin. 2018;26:1508-15.

34. Zou Q. Experimental instruction in plant phyiology. Beijing: China Agriculture Publishing House; 2000.

35. Hao ZB, Cang P, Xu Z. Phytophysiological experiment. Harbin: Harbin Institute of Technology Press; 2004.

36. Zhang ZA, Zhang MS. Experimental instruction in plant physiology. Changchun: Jilin University Publishing House; 2006.

37. Zhu AM, Zhang YX, Wang XU, Tian YL. Effects of autumn cutting on the non-structural carbon and nitrogen content in the root collar of alfalfa. Acta Prataculturae Sinica, 2018, 27(1): 86-96.

\section{Figures}

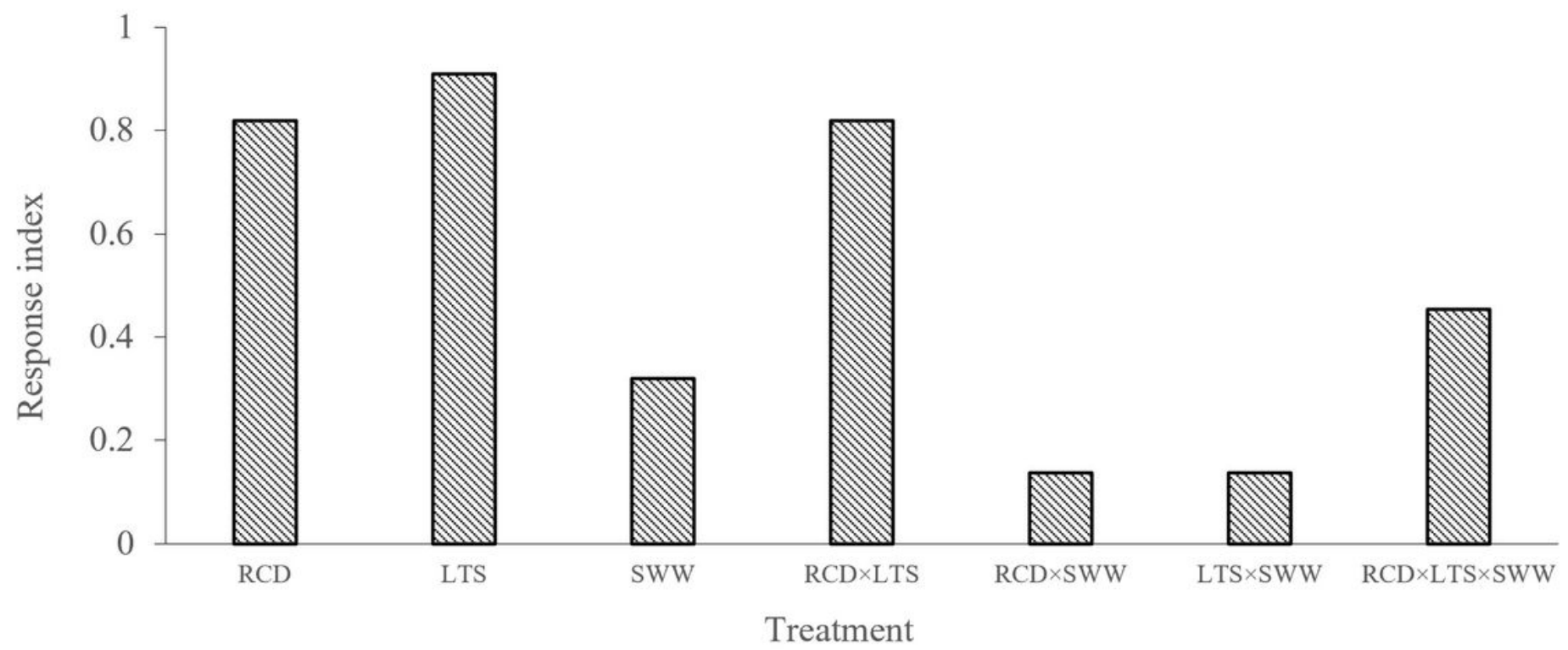

Figure 1

Effect of treatment and interaction on response index. RCD, LTS and SWW represent the alfalfa root collar diameter, low-temperature stress and simulated winter irrigation treatment, respectively. RCD $\times$ LTS, RCD $\times S W W, L T S \times S W W$ and RCD $\times$ LTS $\times$ SWW represent the interactions among the RCD and the treatments. 


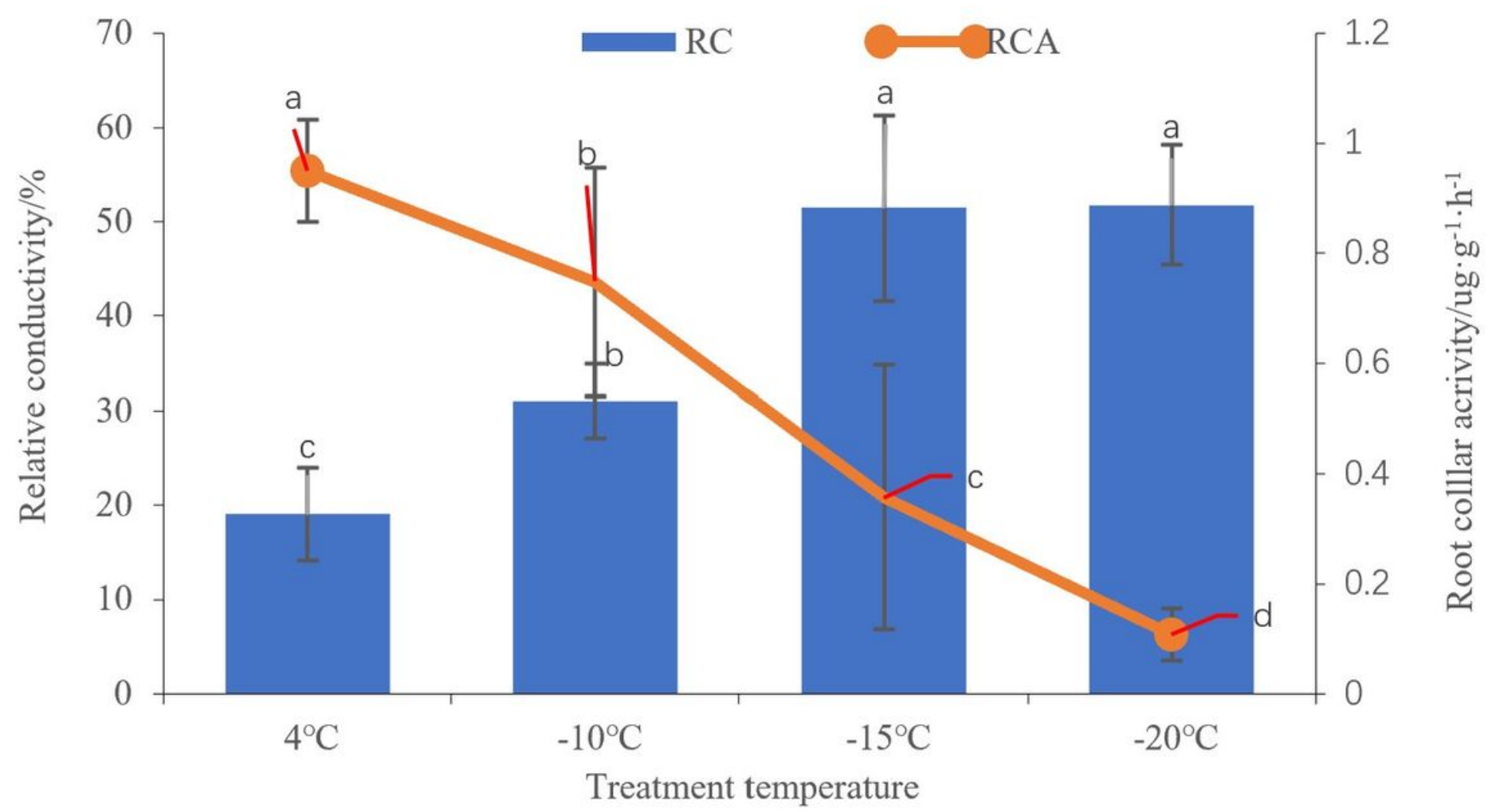

\section{Figure 2}

Effect of low-temperature stress on the relative conductivity and activity of alfalfa root collars. RC and RCA refer to the relative conductivity and activity of the root collar, respectively. $4^{\circ} \mathrm{C},-10{ }^{\circ} \mathrm{C},-15^{\circ} \mathrm{C}$ and $-20^{\circ} \mathrm{C}$ refer to the target temperatures for the alfalfa roots under the low-temperature treatments. Different lowercase letters indicate that the difference between low-temperature treatments was significant at the 0.05 level. 

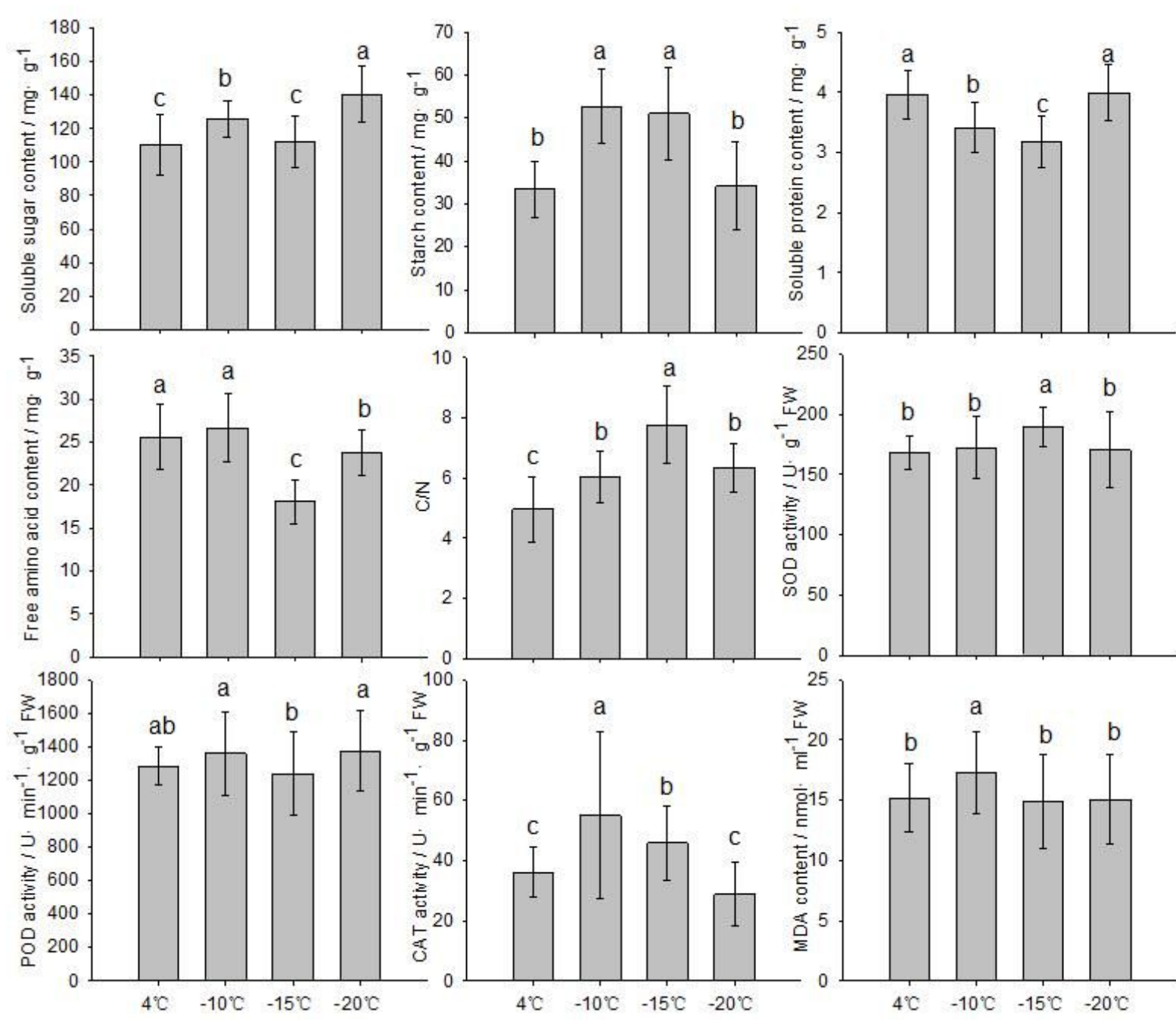

Treatment temperature
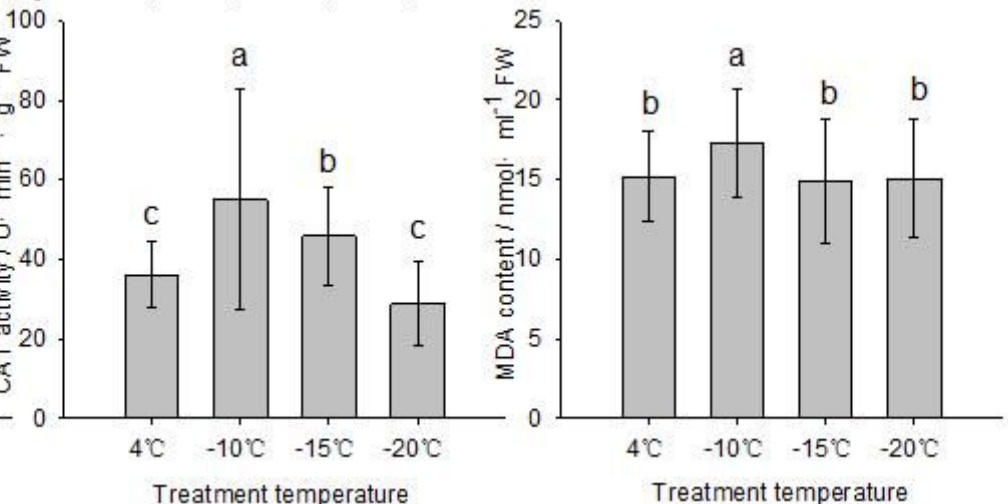

Figure 3

Effects of low temperature stress on physiological and biochemical indexes of alfalfa root collar. SOD, POD, CAT, MDA and C/N refer to superoxide dismutase activity, peroxidase activity, catalase activity, and the nonstructural carbon to nitrogen ratio, respectively. Different lowercase letters indicate that the differences among low-temperature treatments were significant at the 0.05 level. 


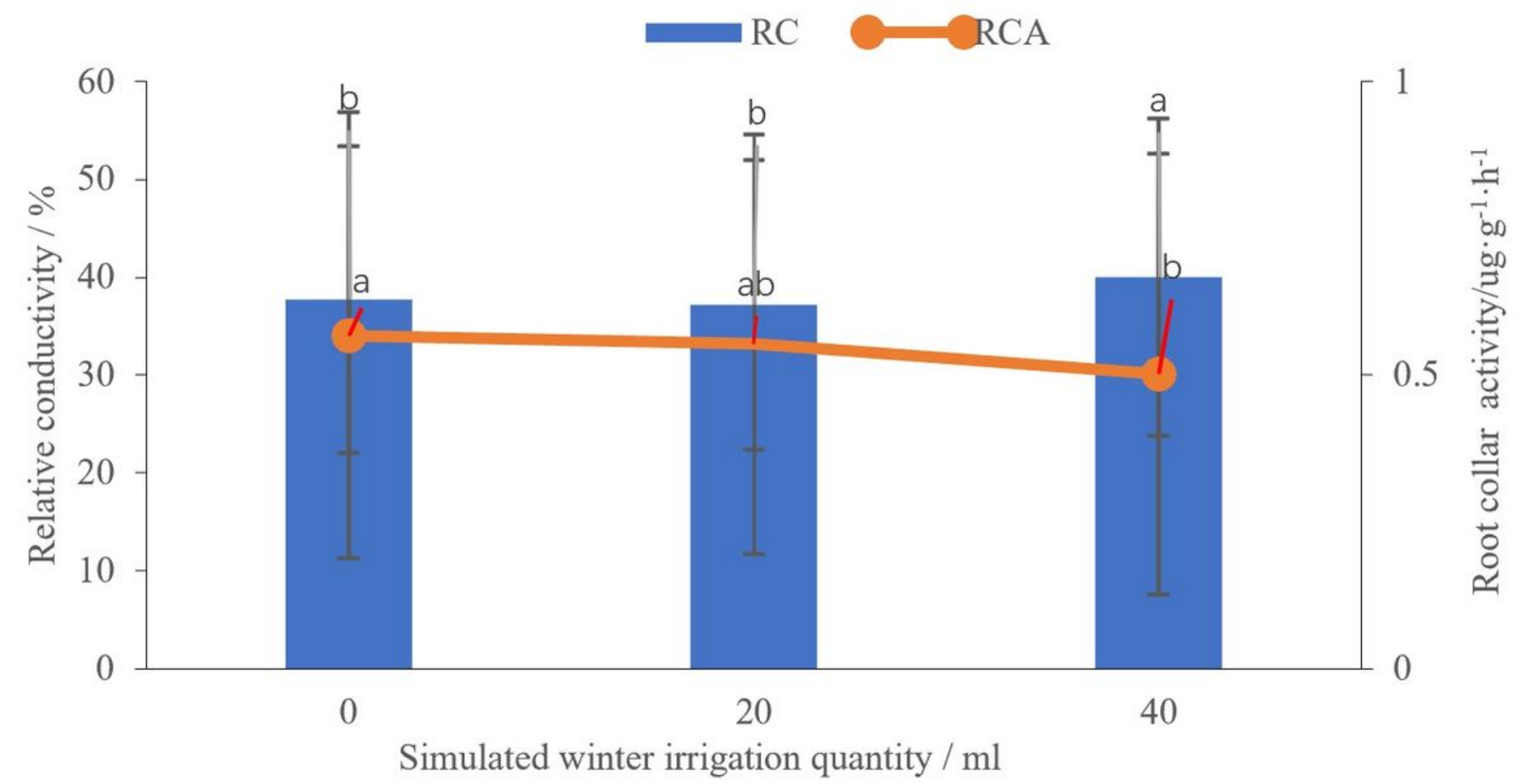

\section{Figure 4}

Effects of simulated winter irrigation on the relative conductivity and activity of alfalfa root collars. 0,20 and 40 represent the simulated winter irrigation treatments for the alfalfa roots, and different lowercase letters indicate that the difference between simulated winter irrigation treatments was significant at the 0.05 significance level. 

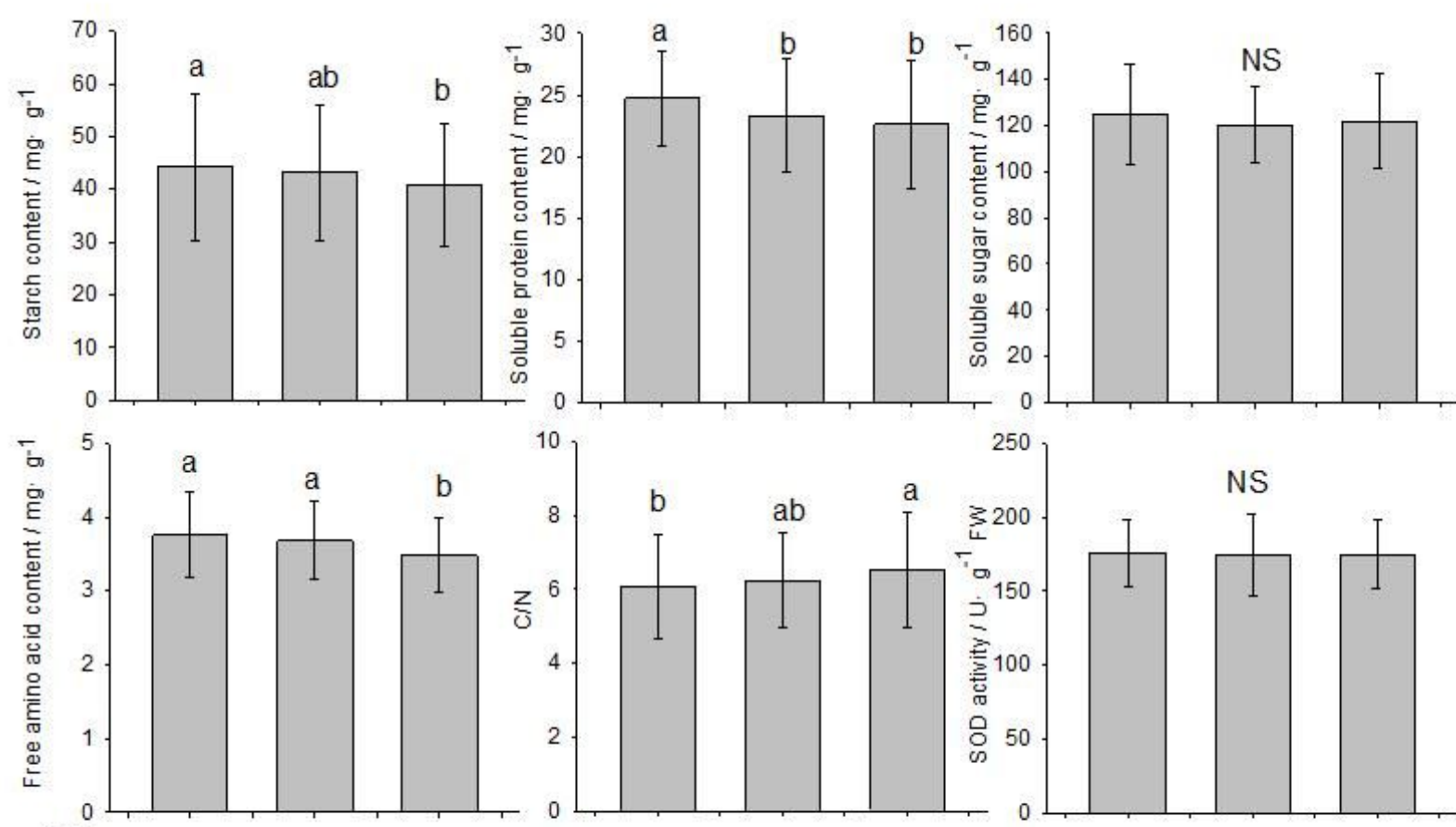

(
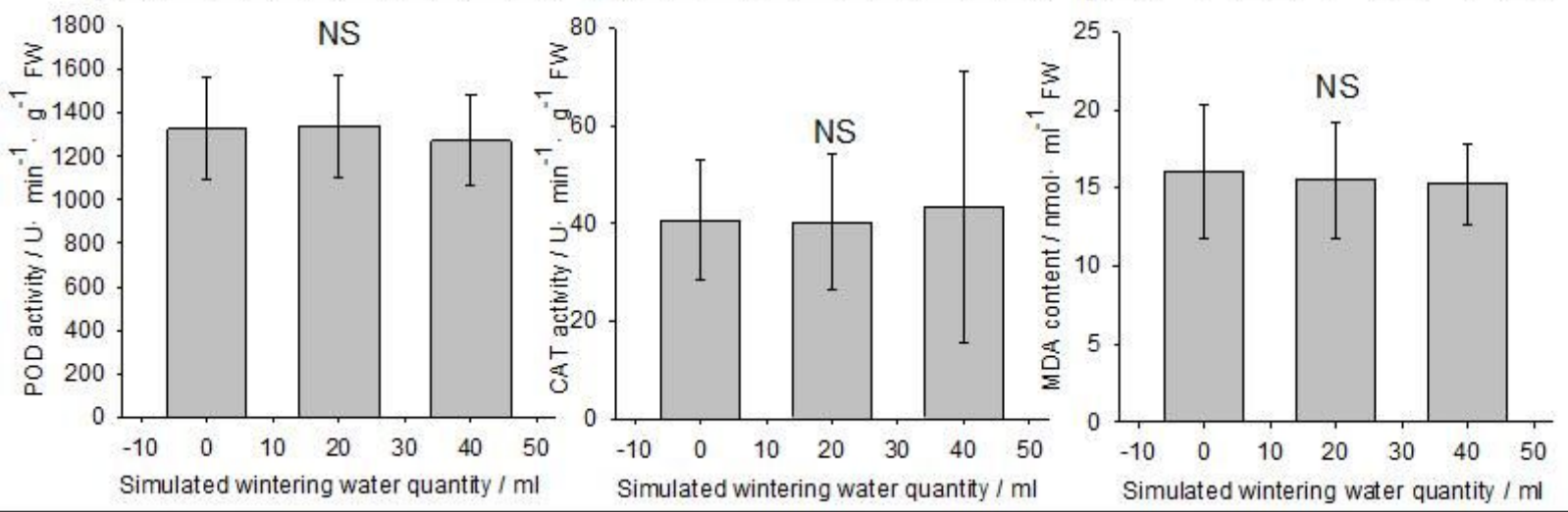

\section{Figure 5}

Effects of simulated winter irrigation on the relative conductivity and activity of alfalfa root collars. SOD, POD, CAT, MDA and C/N refer to superoxide dismutase, peroxidase, and catalase activity and the nonstructural carbon to nitrogen ratio, respectively. Different lowercase letters indicate that the difference between simulated winter irrigation treatments was significant at the 0.05 level. 


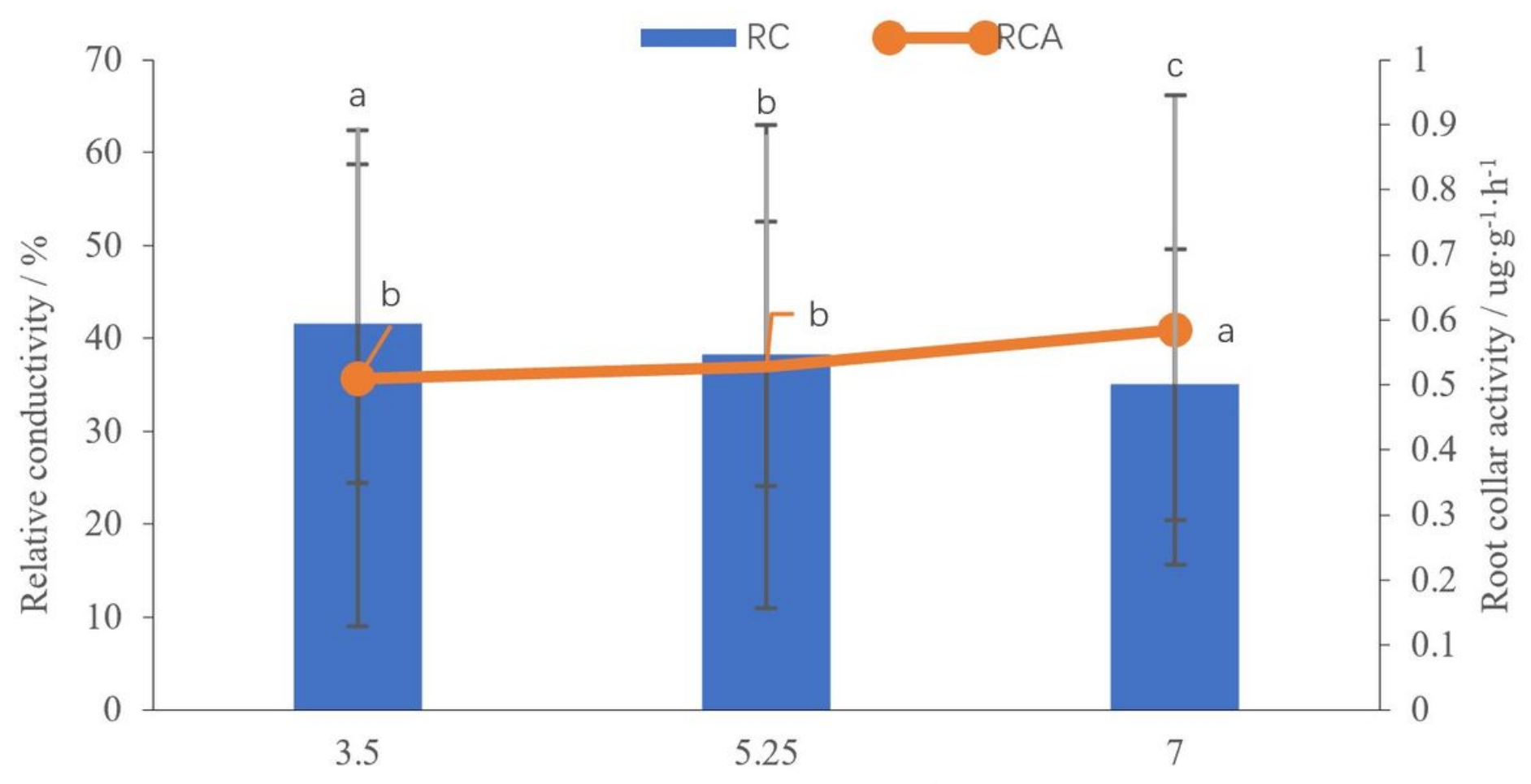

Alfalfa root collar diameter $/ \mathrm{mm}$

\section{Figure 6}

Effect of root collar diameter on the relative conductivity and activity of alfalfa root collars. Different lowercase letters indicate that the difference between root collar diameter classes was significant at the 0.05 significance level. 


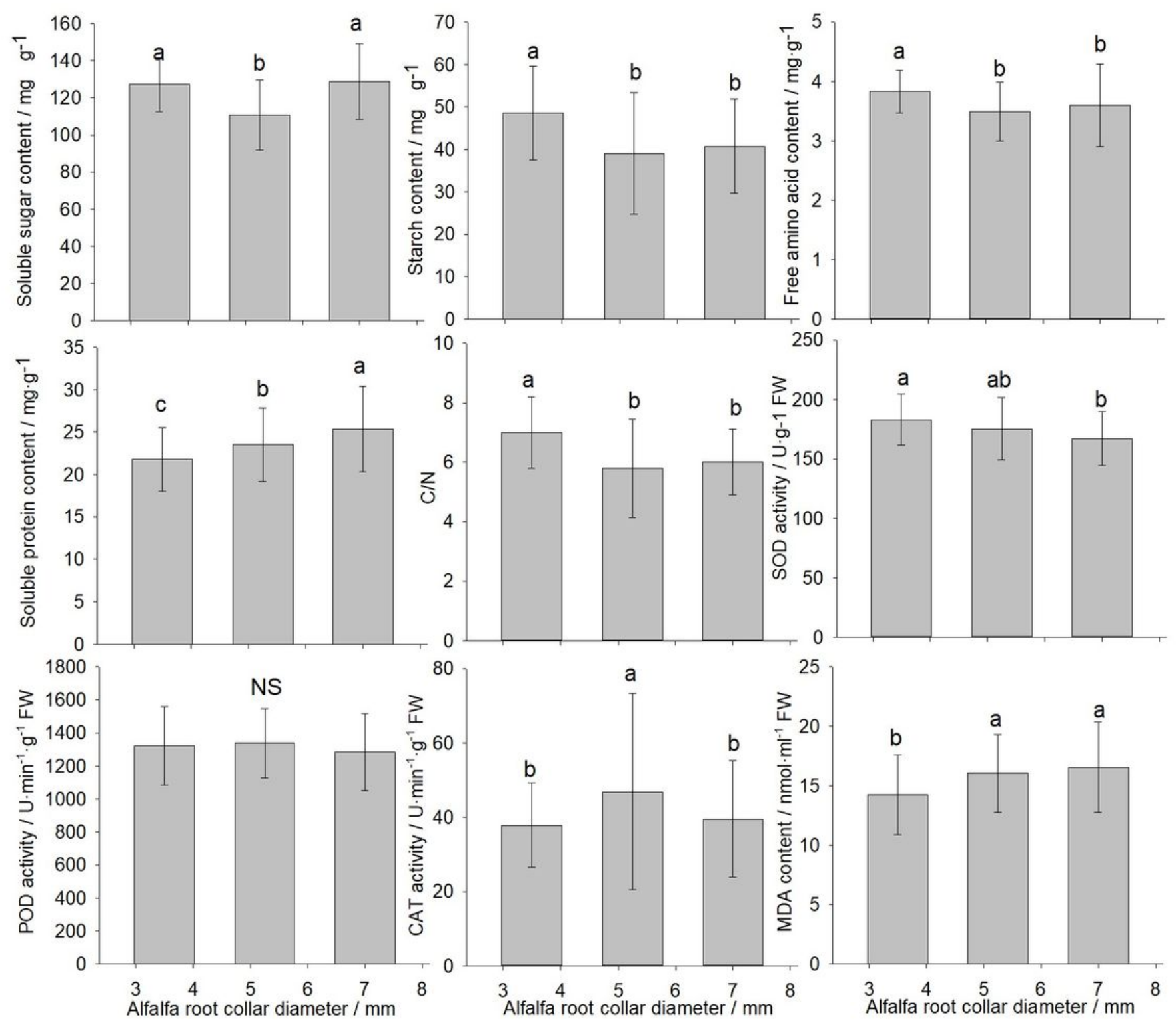

Figure 7

Effect of root collar diameter on the relative conductivity and activity of alfalfa root collars. SOD, POD, CAT, MDA and C/N refer to superoxide dismutase, peroxidase, and catalase activity, and the nonstructural carbon to nitrogen ratio, respectively. Different lowercase letters indicate that the difference between root collar diameter classes was significant at the 0.05 significance level.

\section{Supplementary Files}

This is a list of supplementary files associated with this preprint. Click to download.

- rawdata.xlsx 